\title{
Design of parametric software tools: optimizing future health care performance by integrating evidence-based knowledge in architectural design and building processes
}

\author{
J. B. Sabra \& M. Mullins \\ Department of Architecture, Design and Media Technology, \\ Aalborg University, Denmark
}

\begin{abstract}
The studies investigate the field of evidence-based design used in architectural design practice and propose a method using 2D/3D CAD applications to: 1) enhance integration of evidence-based design knowledge in architectural design phases with a focus on lighting and interior design and 2) assess fulfilment of evidence-based design criterion regarding light distribution and location in relation to patient safety in architectural health care design proposals. The study uses 2D/3D CAD modelling software Rhinoceros 3D with plug-in Grasshopper to create parametric tool prototypes to exemplify the operations and functions of the design method. To evaluate the prototype potentials, surveys with architectural and healthcare design companies are conducted. Evaluation is done by the administration of questionnaires being part of the development of the tools. The results show that architects, designers and healthcare design advisors recon the tool prototypes as a meaningful and valuable approach for 1) integrating and using evidence-based information; and 2) optimizing design processes and health care facility performances. Further study focuses on parametric information relations in Building Information Modelling projects.

Keywords: hospital lighting design, evidence-based design, patient safety, architectural design, building information modelling, parametric design, observation and questionnaires, prototypes.
\end{abstract}




\section{Introduction}

The field in which the studies documented in this paper operate is architectural design practice and research within optimization of contemporary design processes in hospital design with a focus on the role of the architect and how to implement the many facetted factors, parameters, standards and needs from the parties involved in the building process. Experience and studies show that certain issue are involved around the implementation and assessment of Evidence-Based Design (EBD) parameters in hospital design [1].This paper explores how to digitally transcend the sum of evidence-based input parameters into a digital strategy for systemization. The offset is the development of a software based assessment and evaluation method of EBD criteria. As exemplification the paper introduces key topics of investigations in lighting design and patient safety along with a parametric tool prototype developed around architectural design strategies for a patient bedroom at a hospital facility.

\section{Optimization technologies in the design process}

In recent years technical professions and industries have been developing and embedding innovative technological instruments to calculate or simulate performance of architecture and design. By using optimization and rationalization algorithms upon a structure better design can be achieved [3]. By exploring the fields of architecture, evidence-based design and software technologies a method of approach is invented, one that provides information and evidence to the design process as a way to meet demands and criteria defined in e.g. a hospital project description [2].

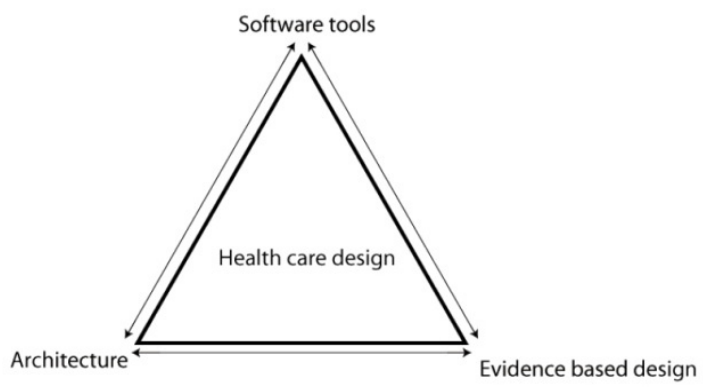

Figure 1: The explorative study from where the parametric tool development is initiated.

\subsection{Purpose of a digital tool}

Focusing on EBD in the design of healthcare architecture is a focus on the relations between the constructed environments, the performance of the building, the users of the building and the perception of space and context. 
With regards to the existing research catalogue presented by Ulrich et al. [1] and Frandsen et al. [4] the evidence material herein is found reliable and usable where articles and papers prove relations between the medical sciences and architectural and environmental factors and parameters.

Evidence-based knowledge is used for two purposes; 1) to inform the designer and 2) to derive parameters based on evident material to be programmed in software. In order to increase the productivity in praxis the parametric tool combines information databases with actual real-time design modelling.

A method of approach to support the architects in controlling demands, own visions, and input alongside providing evident baseline data in the early design process, is to develop a system that can hold relevant information and give reliable associative feedback when valid information is needed prior to decisionmaking. Such a system is a dynamic user-interactive tool based on parametric associative design variables. A tool capable of; linking knowledge, storing information and data, increase communication and ensure validation, evaluation and control of performance in an optimizing process of design and task specific quality of health care buildings.

The development software used in these studies is Grasshopper 3D, a plug-in for the modelling software Rhinoceros $3 \mathrm{D}$, an associative parametric componentbased geometric modelling software [5]. Being associative in its nature, a potential prototype-user is able to change the design parametrically without loosing information or having to remodel it from the beginning.

\subsection{Parametric setup based on health care projects}

The topics lighting design and patient safety are investigated from a parametric and evidence-based design perspective.

The evidence indicates that well-designed physical settings plays an important role in making hospitals safer and more healing for patients and better places for staff to work [1].

Lighting design and patient safety is referred to as relations between the physical factors of plan solutions, interior design, materials and equipment in creating an environment with focus on the staffs and the patient's situation.

Seen from a parametrical point of view these topics pose a straightforward process because of the possibilities of working with floor plans, object location and distance measurement.

Following are exemplifications of parameters regarding light, patient safety and the floor plans used in the tool development:

- Luminance, glare, daylight and artificial lighting

- $\quad$ Single bed or multiple bedrooms

- Height of rooms, windows, doors, interior

- Distance to bathroom, distance to nurse station

- Location of bed, amount of space, boundary space

The software tool identifies and assesses the objects and elements by running evaluations on the floor plan delivered by the architect early in the process. The 
assessment of the floor plan identifies specific facility conditions of the architectural plan and design, where the lighting design and the quality of patient treatment is compromised.

\section{Method of approach}

The hospital projects Aalborg House of Medicine, Aalborg, Denmark and The New University hospital project at Skejby, Denmark are used as case studies in the understanding of processes, measures and requirements regarding lighting design in health care architecture. The architectural company Friis \& Moltke, Aalborg, Denmark, the healthcare consultancy firm ArchiMed, Copenhagen, Denmark and architectural students at Aalborg University, Denmark participates throughout the studies in interviews and surveys to obtain data and evaluation of the proposals and results of the studies and prototypes.

\subsection{Computer-supported cooperative work}

The method of Computer-Supported Cooperative work is used to unfold exploration of Strategic planning, Human-Computer Interaction and Software engineering, topics relevant for the studies [6, 7].The method focus on practice and work-oriented design research in the development of applications and systems, a view contemplating the more abstract, social and organizational work aspects of user and company practice as opposed to more traditional software engineering with emphasis on physical concrete artifacts in procedures and tasks [6]. Further, the project investigations uncover design aspects around the four main topics: Context, User, Task and Technology [8].

\subsubsection{Scenario based design}

The tool design phase is initiated by work with scenarios of possible future tasks and tendencies of practice and context, a field of low tangibility regarding the system design requirements [6]. A shift is made into the Human-Computer Interaction (HCI) field with focus on scenario studies of previous and present user practice and work routines and is ended with design in software engineering exploring the tangible tool prototypes, the initial parts of a proposed system model [7]. The scenario-based design model focus on architectural practice in health care design, with EBD as main focus under which the architectural designer is considered primary user and the architectural practice as immediate design context. The scenarios are tested through a survey by a group of selected architects and architecture and design students.

\subsection{Design and implementation}

Prototyping is used as a method to iteratively develop tool functions as the design exploration progresses [9].

During each design phase, to meet specific user requirements, relational models are developed as separated parts of the whole system. Prototypes are 
developed when basic functions needs exploration and consist of small scripts that are tested ahead of the design of larger prototypes.

\subsection{Prototype evaluation; surveys, user reviews and questionnaires}

The prototypes are tested through a survey to test the ability to bridge evidencebased design information with design tasks. The survey is conducted as an expert user review with emphasis on cognitive walkthrough of the users to test the overall usability and functionality of the tools [10]. The main purpose of conducting the user review is to provide:

- A review of the usability regarding evidence-based design of the tool.

- Identification of problematic areas and issues, EBD- and applicationwise within the tool for use in development iterations.

The benefit of the tools is assumed through a questionnaire to get concise feedback on specific subjects [11].

\section{Prototype development}

Based of the empirical studies of the project, prototype development scenarios are conducted in order to determine the requirements and functionality of the tool prototypes.

\subsection{Prototype scenario model}

The scenario analysis methods of both strategic planning and human-computer interaction reveal information of actors, background and assumptions of work environment, goals and objectives and the sequences of actions and events.

The scenario is the foundation of the prototype application design:

- The user group is limited to only focus on the architect's role as designer in the project process.

- Technologically the focus is on CAD drawing and modelling in 2D and to some extent also 3D.

- The functionalities are that of visualization of undesirable architectural propositions and design decisions.

- The references to evidence-based information regarding design tasks are embedded in the prototype design.

\subsection{Prototype development strategy}

The prototypes are developed with emphasis on test and trial of the functions derived from the requirement analysis. The descriptions of the prototypes are based on their operational level. Focus is on the implementation of evidencebased knowledge in the actual programming in Grasshopper. The topic is lighting and safety with focus on floor plan and bedroom design of a hospital. 


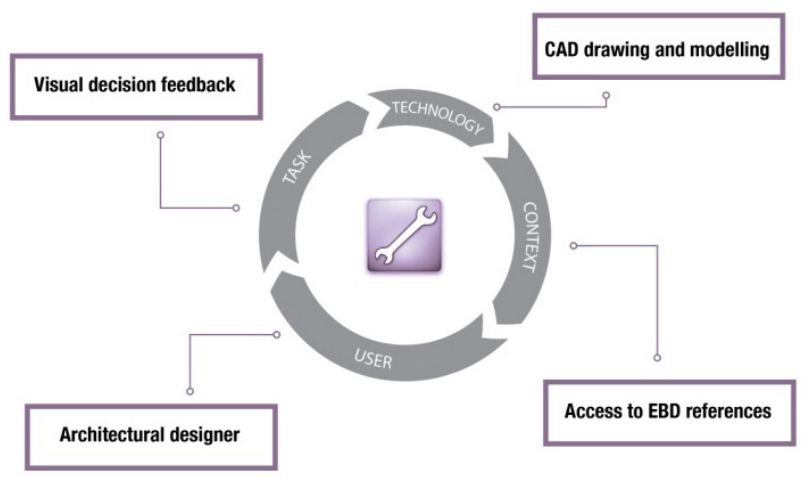

Figure 2: $\quad$ The prototype scenario.

\subsubsection{Main purpose and prototype goals}

Derived from the scenario models the following prototype goals have been embedded:

- Linkage between design issues and EBD information

- Usage on different scale and detail level in projects

- Weigh user participation through sketch and feedback

- Ability to steer, control and maintain overview of goals and tasks

\subsubsection{Parametric definition}

The prototypes consist of a set of basic functions each with a predefined number of different operations all of which have specific sets of parameters, definitions and relations to other parameters. The overall method for the parametrical definitions is approached by identification of the following parametric typologies and their relations [12]:

- Driver (parameter)

- Driven (single parameter or set of parameters) and

- Constraining parameters (boundaries, limitations and conditional statements)

\subsubsection{Overall prototype functions}

The empirical and qualitative data contributes to the parametric setup and scripting of the prototype by the extended clarification of factors and parameters needed to improve the design of the healthcare facilities.

The prototypes offer the architect the possibility to design a room with optimal lighting and patient safety parameters.

The CAD model is either loaded into Grasshopper 3D or the objects are rearranged right away. A list of objects is available for selection, each parametrically connected to the other. The prototype support both $2 \mathrm{D}$ and $3 \mathrm{D}$ objects in the planning. 
Table 1: $\quad$ Bedroom prototype supportive functions.

\begin{tabular}{|c|c|c|c|c|}
\hline Design tasks & $\begin{array}{l}\text { Prototype } \\
\text { functions }\end{array}$ & $\begin{array}{c}\text { EBD } \\
\text { functions; } \\
\text { lighting } \\
\text { design }\end{array}$ & $\begin{array}{c}\text { EBD } \\
\text { functions; } \\
\text { patient } \\
\text { safety }\end{array}$ & $\begin{array}{l}\text { Other func- } \\
\text { tions }\end{array}$ \\
\hline $\begin{array}{l}\text { Selecting or } \\
\text { importing } \\
\text { objects }\end{array}$ & $\begin{array}{l}\text { Calculation } \\
\text { of free } \\
\text { space, room } \\
\text { size }\end{array}$ & $\begin{array}{c}\text { Window } \\
\text { location, } \\
\text { material and } \\
\text { size }\end{array}$ & $\begin{array}{l}\text { Size of room } \\
\text { and free } \\
\text { space for } \\
\text { optimal } \\
\text { work } \\
\text { routines }\end{array}$ & $\begin{array}{l}\text { Participation } \\
\text { of user } \\
\text { representa- } \\
\text { tives }\end{array}$ \\
\hline $\begin{array}{c}\text { Arrangement } \\
\text { of objects }\end{array}$ & $\begin{array}{l}\text { Managing } \\
\text { EBD } \\
\text { information }\end{array}$ & $\begin{array}{c}\text { Geographical } \\
\text { location and } \\
\text { orientation }\end{array}$ & $\begin{array}{l}\text { Minimal } \\
\text { space for } \\
\text { utilities }\end{array}$ & $\begin{array}{l}\text { Documentati } \\
\text { on of design } \\
\text { criteria }\end{array}$ \\
\hline \multirow[t]{2}{*}{$\begin{array}{l}\text { Selection of } \\
\text { parameters } \\
\text { for the room's } \\
\text { specification }\end{array}$} & $\begin{array}{l}\text { Calculate } \\
\text { EBD credit } \\
\text { value }\end{array}$ & $\begin{array}{c}\text { Experienced } \\
\text { view through } \\
\text { window }\end{array}$ & $\begin{array}{l}\text { Visibility } \\
\text { and distance } \\
\text { to nursing } \\
\text { station }\end{array}$ & $\begin{array}{l}\text { Design } \\
\text { process using } \\
\text { the prototype }\end{array}$ \\
\hline & & $\begin{array}{l}\text { Artificial } \\
\text { lighting } \\
\text { sources, } \\
\text { levels and } \\
\text { colours }\end{array}$ & $\begin{array}{c}\text { Infection } \\
\text { control } \\
\text { Distance to } \\
\text { bathroom }\end{array}$ & \\
\hline
\end{tabular}

The function of analysing the distance and visibility to the nearest nurse station or natural view through the window contributes to the evaluation and assessment of the level of lighting quality and patient safety of the design proposal.

The designer receives an immediate EBD credit score and a list of fulfilment and error notifications on behalf of the design decisions. This serves as documentation of the design process and expected impact on the immediate health care design proposal.

\subsection{Case: The bedroom prototype}

\subsubsection{Purpose}

The topic of this tool prototype is lighting design and patient safety and how the near environment of the patient can contribute to a more safe in-house hospital stay with focus on experienced lighting atmosphere [15]. The prototype is based on parameters and evidence regarding the organization of the patient bedroom.

\subsubsection{Definition}

Evidence-based research indicates that the organization and size of a bedroom and the objects that fill it, contributes to the level of safety, that being levels of hygiene infections, patient and staff injury and infection related deaths [1]. 
There are 2 entry paths using the application prototype during the design of the bedroom:

- The application requires no detailed layout of the bedroom (CAD drawing/model) prior to the use of the tool.

- The architect loads an already defined CAD outline drawing or model of the bedroom into the prototype for further detailing and assessment.

Table 2: $\quad$ Parametric setup of the bedroom module.

\begin{tabular}{|c|c|c|}
\hline Driver & Driven & Constraints \\
\hline $\begin{array}{c}\text { The objects } \\
\text { midpoint, light- } \\
\text { emitter vectors }\end{array}$ & $\begin{array}{c}\text { The intersections between } \\
\text { objects and emitters }\end{array}$ & Bedroom size boundaries \\
\hline $\begin{array}{c}\text { The number of } \\
\text { objects }\end{array}$ & The conflict list & $\begin{array}{c}\text { The EBD accreditation } \\
\text { percentage }\end{array}$ \\
\hline $\begin{array}{c}\text { The parameters } \\
\text { chosen for } \\
\text { evaluation }\end{array}$ & $\begin{array}{c}\text { Wall curves intersections } \\
\text { with light vectors from } \\
\text { emitters }\end{array}$ \\
\hline
\end{tabular}

\subsubsection{Development}

A list of procedural task-descriptions guides the architect through the use of the tool. The architect selects the objects that are to be implemented in the room and relocates them accordingly. Once the locations of the objects are specified the script calculates the objects' midpoints and the distances between the objects to determine the spatial relations and object-free zones. Each conditional criterion is assessed and sent to one of the evaluation scripted lists.

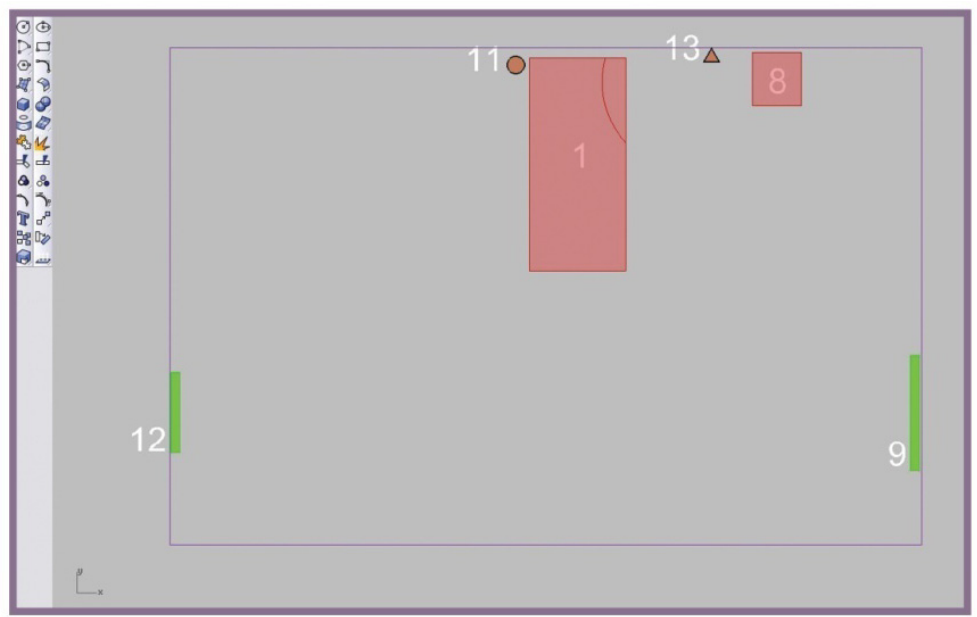

Figure 3: The objects in the top right corner are intersecting and conflicting. 


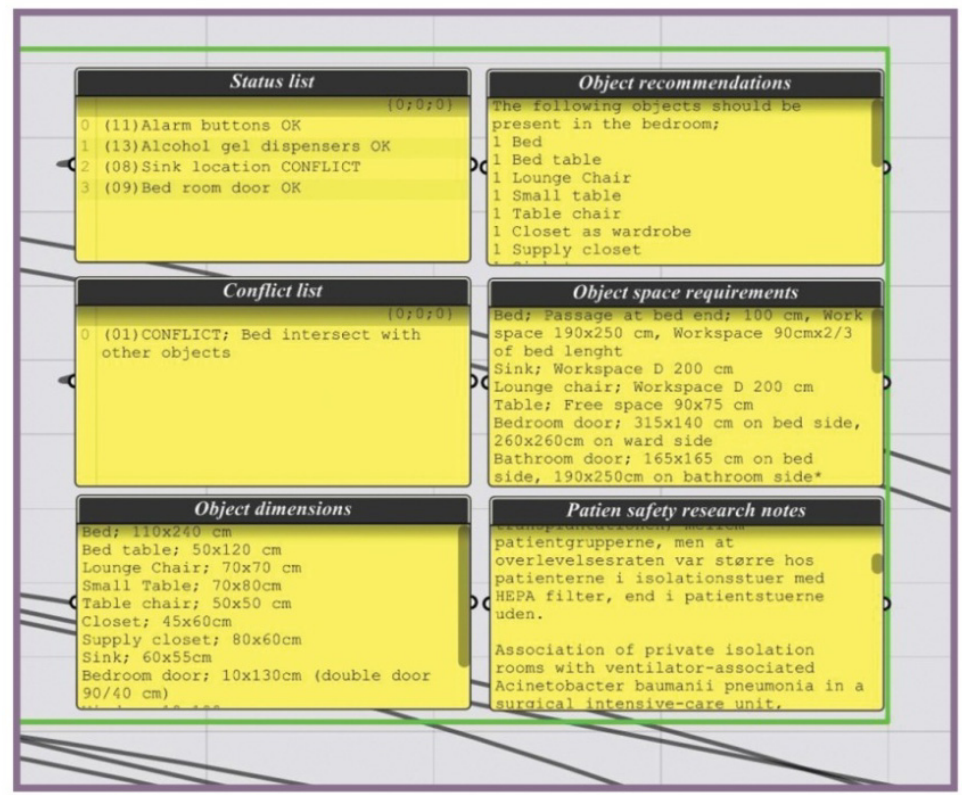

Figure 4: Example of interface when reading the output conflict between bed and sink.

\subsubsection{Feedback}

A graphical representation of the bedroom is present during the use of the prototype. Specific colours define the relational zones of each of the objects. Intersections between objects are emphasized and an alert message is executed in the alert panel. Light vectors are highlighted upon intersection with objects.

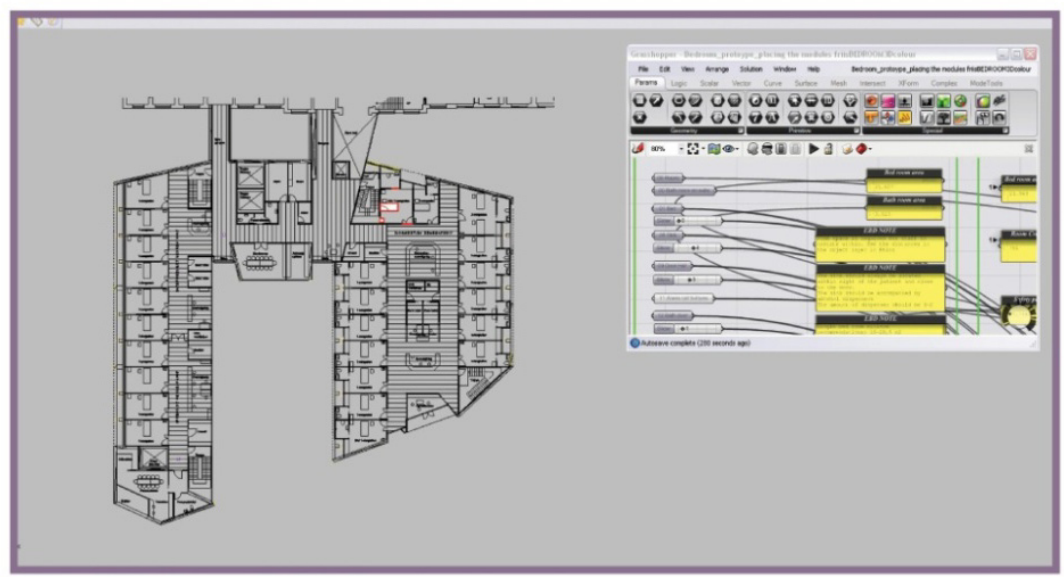

Figure 5: The floor plan of the proposal for the new medical wing at Thisted Hospital. 


\subsection{Implementation examples of existing floor plans}

The bedroom module is used with the plan drawings of the Thisted Hospital proposal, by Friis \& Moltke, Aalborg, Denmark, 2010.

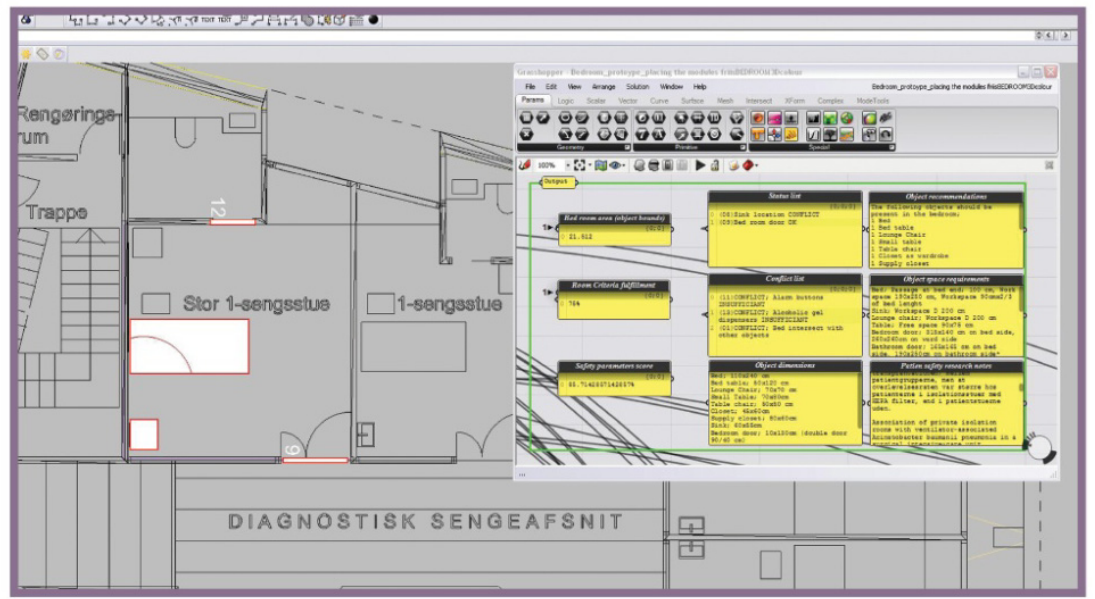

Figure 6: Test of the bedroom plans of the Thisted hospital proposal. Bed and sink is highlighted and in conflict.
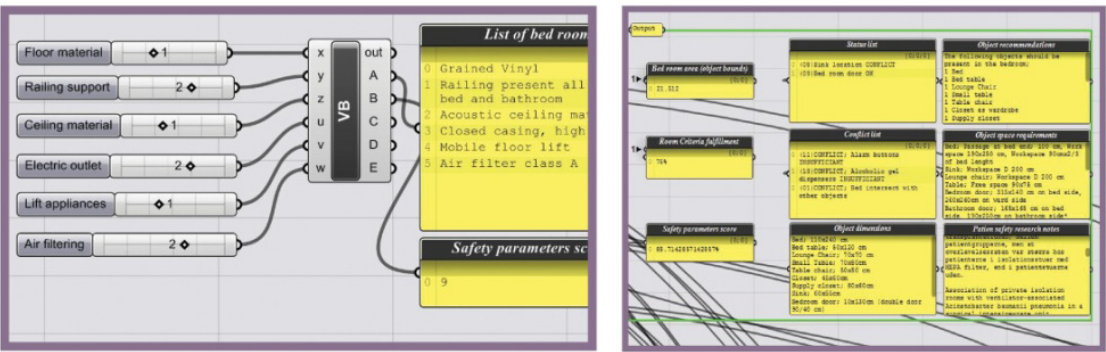

Figure 7: Left: A section of the parameter list of the EBD criteria. Right: Conflict notifications from the test of the Thisted Hospital design proposal.

\section{Conclusions}

The conclusions in this paper encompass the results throughout the studies and a perspective on future work areas within the study field.

\subsection{Project approach and tool methodologies}

Investigations are made in the field of architectural practice and design of health care buildings. Empirical methods are used to obtain the knowledge needed to be 
able to develop the prototypes. The fields of study are; building design process, architectural design process, evidence-based design, lighting design and patient safety.

From the explorations it is found that for the tool to support evidence-based design concepts should encompass the following functions:

- $\quad$ Provide, store and document EBD related data

- Evaluate and control the parametrical defined EBD concepts and criteria in the design proposal

From developing the prototypes it is found that diverse approaches to EBD data are needed in order to both translate it into parametrics, but also fit the assignment of creating a tool of value for the architects. The two types of EBD data used are; 1) guidelines derived from physical work environmental statements e.g. minimal illumination levels at the nurse's workspace and, 2) evidence-based criteria of both descriptive and non-descriptive character, e.g. the view towards natural environments and the perceived space around the patient.

Hence the developed prototypes focus on the evaluation of the physical measures of the bedroom [13]. The specific functionality of the prototypes as well as their construct is tested through an expert user review at the architectural practice.

Through a survey of the prototype development phase the tools are found to be valid and usable in design work, but primarily for the lesser EBD experienced architect and designer. The supportive functions of the tools are more related to the architects' need of support and information, than the control of the actual design plan.

The tools are in general found to hold significant future promise and further development. The feedback from the survey is considered reliable as indicator of the issues and possibilities of the tools.
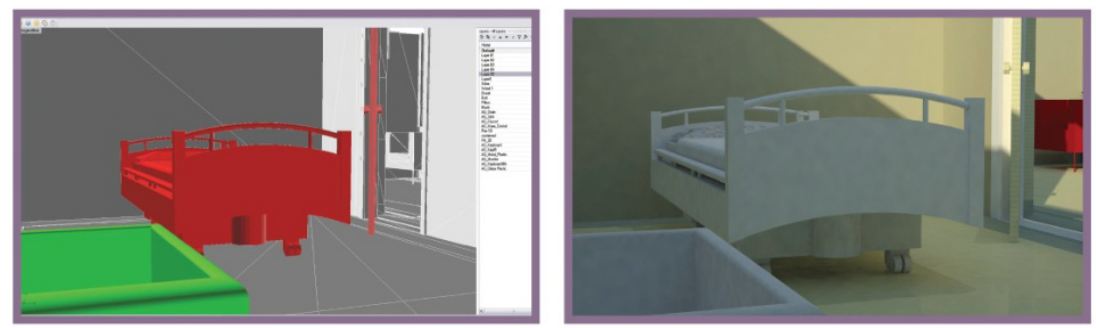

Figure 8: Left: Rendered bitmaps as documentation. In this case the bed is located to close to the door and emphasized. Right: Visual feedback, e.g. natural light and artificial light sources improves the evaluation of the design. 


\subsection{Evidence-based design and parametrics}

Derived from the expert review at the architectural company Friis \& Moltke, Aalborg, Denmark, it is found that the sudden access to the many layers of information normally hidden from the perception of the designer, justifies the implementation of the tools in praxis. The parametric logic of the application is not biased by deadlines, creative visions and preferences regarding specific design solutions. As a knowledge based tool, the applications have the potential of unifying stakeholders across the different parts of the building process by offering standard descriptions of EBD concepts and criteria, listing conflicts and design issues and sharing knowledge and documentation of the design process.

\subsection{Future work and development; Embedding evident material documenting perception and sensing parameters}

The prototypes are designed to rely on measurable geometrical statements and conditions. Letting the architect choose parameters from a checklist is a method of encompassing non-logistical non-geometrical parameters in the EBD tool. Extending the embedding of evidence on light perception, sensing and experience-based relations of lighting atmosphere [15] pose the next assignments in the development phase of the studies. The EBD tool has a strong possibility to be implemented as a learning tool for architects and designers. The next phase of development will focus on the strategy for creating relational constraints and connections between data, source and references of EBD. The platform to develop in the future should be integrated in the BIM software and the object based modelling concepts, e.g. Autodesk Revit [14]. These technologies have large data capacities and well-established financial foundations meeting new demands and requirements of contemporary innovative markets.

Finding that the architectural design practitioners are willing to apply evaluation algorithms to their design proposals, indicates that this is a field that holds much potential, explorative, academic and financial. The parametric tools displayed in this paper have the possibility to encompass all the information of EBD but it is nonetheless the user of the tool who can interpret the data and rightfully apply it for a specific context. The parametric tool is still just a tool- a support for the architect, the designer and whomever have the interest in applied evidence-based design concepts in architecture and lighting design.

\section{References}

[1] Ulrich, R. S., Zimring, C., Zhu, X., et al., A review of the research literature on evidence-based healthcare design, 2008, HERD, 1(3), 61.

[2] GODTSYGEHUSBYGGERI,http://www.godtsygehusbyggeri.dk/Tv-ae-rgaa-ende\%20Emner/-OE-konomistyring.aspx

[3] Kolaveric, B. \& Malkawi, A. M., Performative architecture, Beyond instrumentality, Spon Press, NY, 2005. 
[4] Frandsen, A. K., Ryhl, C., Folmer, M. B., et al., Helendearkitektur, Institut for Arkitekturog Design, DanskeRegioner, Denmark, pp.21-56, 2009.

[5] GRASSHOPPER3D, www.grasshopper3d.com

[6] Carroll, J.M. \& Go, K., The Blind Men and the Elephant: Views of Scenario-Based System Design, The Pennsylvania State University, USA, 2004.

[7] Brown, C. M., Human-computer interface design guidelines, Intellect Ltd., Great Britain, 1999.

[8] Galletta, D. \& Zhang, P., Human Computer interaction and management information systems: Foundations, M. E. Sharpe Inc., New York, 2006.

[9] Baynon-Davies, P., Rapid Applications Development; A review and case study, Kane Thompson Centre, USA, 1998.

[10] Plaisant, C. \& Shneiderman, B., Designing the User Interface: Strategies for Effective Human-Computer Interaction, 4th ed., Addison-Wesley, University of Maryland, College Park, 2005.

[11] Frary, Robert B., Hints for designing effective questionnaires. Practical Assessment, Research \& Evaluation, Virginia Polytechnical Institute, USA, 1996.

[12] Kilian, A., Design exploration through bidirectional Modeling of constraints, MIT Press, Massachusetts, USA, 2006.

[13] O’Neill, M. J., Evaluation of a conceptual model of architectural legibility, Environment \& Behavior, 1991a, 23(3), 259.

[14] AUTODESKREVIT, www.usa.autodesk.com/adsk/servlet/pc/index?siteID=123112\&id=3781831

[15] Stidsen, L., Kirkegaard, P.H. \&Fisker, A.M., Design proposal for pleasurable light atmosphere in hospital wards, Knemesi, Italy, pp. 366, 2010. 